\title{
Percepção dos homens quanto ao exame digital da próstata
}

\section{Men's perception of digital prostate examination}

\author{
Leonardo Alves Rodrigues dos Santos ${ }^{1}$, Rondinele Amaral da Silva ${ }^{2}$, \\ Leandro Felipe Mufato ${ }^{3}$, Grasiele Cristina Lucietto ${ }^{4}$, \\ Joely Maria de Oliveira ${ }^{5}$, Juliana Benevenuto Reis ${ }^{4}$
}

\section{Resumo}

Objetivo: compreender os significados do exame digital da próstata para o homem que sofre de câncer de próstata. Material e Método: trata-se de um estudo descritivo, exploratório, com abordagem qualitativa. Sete homens, que vivenciaram o exame digital da próstata, foram entrevistados nesta pesquisa com o uso da técnica de entrevista aberta. Resultados: os dados foram analisados por meio da análise temática e revelaram duas categorias: "Situações que influenciaram a realização ou não do exame de próstata e suas consequências" e "Percepções dos homens durante o exame". Este estudo mostrou que existem fatores que influenciam positivamente a busca de cuidados, tais como: incentivo familiar, conhecimento prévio sobre a doença e importância do diagnóstico precoce. Por outro lado, o preconceito e a falta de conhecimento têm sido fatores que dificultam a busca pelos serviços de saúde, pois, em muitos casos, os pacientes procuram atendimento após o aparecimento de sinais e sintomas, impactando o diagnóstico tardio, levando a mau prognóstico. Conclusão: conclui-se que os profissionais de saúde têm papel fundamental na adesão dessa população ao sistema de saúde por meio de ações educativas para promover o conhecimento sobre o assunto e proporcionar um cuidado humanizado por meio do acolhimento.

Palavras-chave: Saúde do homem. Promoção da saúde. Câncer de próstata.

1 Graduação em Enfermagem pela Universidade do Estado de Mato Grosso, Tangará da Serra, Mato Grosso, Brasil.

2 Mestrado em Ciências Odontológicas Integradas pela Universidade de Cuiabá, Cuiabá, Mato Grosso, Brasil. Docente do Departamento de Enfermagem da Universidade do Estado de Mato Grosso, Tangará da Serra, Mato Grosso, Brasil.

3 Doutorado em Enfermagem pela Universidade Federal de Mato Grosso, Cuiabá, Mato Grosso, Brasil. Docente do Departamento de Enfermagem da Universidade do Estado de Mato Grosso, Tangará da Serra, Mato Grosso, Brasil.

4 Mestrado em Enfermagem pela Universidade Federal de Mato Grosso, Cuiabá, Mato Grosso, Brasil. Docente do Departamento de Enfermagem da Universidade do Estado de Mato Grosso, Tangará da Serra, Mato Grosso, Brasil.

5 Mestranda em Saúde Coletiva pela Universidade Federal de Mato Grosso, Cuiabá, Mato Grosso, Brasil. Docente da Universidade do Estado de Mato Grosso, Tangará da Serra, Mato Grosso, Brasil. E-mail: joely.unemat@gmail.com 


\begin{abstract}
Objective: understand the meanings of digital prostate examination for the man suffering from prostate cancer. Material and Method: it is a descriptive, exploratory study with a qualitative approach. Seven men, who experienced the digital prostate exam, were interviewed in this research using the open interview technique. Results: the data was analyzed through thematic analysis and revealed two categories: "Situations that influenced the performance or not of the prostate exam and its consequences" and "Men's perceptions during the test". This study showed that there are factors that positively influence the search for care, such as: family encouragement, prior knowledge about the disease and the importance of early diagnosis. On the other hand, prejudice and lack of knowledge have been factors that hinder the search for health services, as, in many cases, patients seek care after the appearance of signs and symptoms, impacting the late diagnosis, leading to poor prognosis. Conclusion: it is concluded that health professionals have a fundamental role in the adherence of this population to the health system through educational actions to promote knowledge on the subject and provide humanized care through welcoming.
\end{abstract}

Keywords: Men's health. Health promotion. Prostate cancer.

\section{Introdução}

Os agravos à saúde do homem constituem verdadeiros problemas de saúde pública, pois apresentam altos índices de morbimortalidade por meio dos indicadores. Os coeficientes de mortalidade masculina são consideravelmente maiores quando comparados aos de mortalidade do sexo feminino no decorrer da vida. ${ }^{(1)}$ Frente a este perfil, o Ministério da Saúde (MS) criou a Política Nacional de Atenção Integral à Saúde do Homem (PNAISH), que visa a promover condições e melhorias de saúde voltadas ao público masculino. A política contribui, de forma efetiva, para a redução da morbidade e da mortalidade por meio das ações de enfrentamento racional dos fatores de riscos, capacitação, qualificação dos profissionais de saúde e por meio da facilitação do acesso aos serviços de assistência integral. ${ }^{(1)}$

A PNAISH tem o objetivo de promover ações de saúde na busca por compreender a realidade ímpar masculina, nos seus diversos contextos, de forma a respeitar os diferentes níveis de desenvolvimento e organização dos sistemas locais e tipos de gestão de saúde. Nesse sentido, observase o aumento da expectativa de vida e a redução da morbimortalidade masculina por causas previsíveis e/ou evitáveis nessa população. Ainda, o MS orienta essas ações na atenção integral à saúde do homem, visando a estimular o autocuidado e, sobretudo, o reconhecimento de que a saúde é um direito social básico e de cidadania de todos os homens brasileiros. Esta política está relacionada com a Política Nacional de Atenção Básica (PNAB), que segue as estratégias da humanização, fortalece ações e serviços em redes e cuidados de saúde, em harmonia com os princípios do Sistema Único de Saúde (SUS). ${ }^{(1)}$

Nos homens, o câncer de próstata ocupa o primeiro lugar, sem considerar o câncer de pele não melanoma. A prevalência do câncer de próstata é o sexto tipo mais comum no mundo e representa cerca de $10 \%$ do total de cânceres. No Brasil, em 2020, as estimativas para o triênio 2020-2022 são de 65.840 novos casos de câncer de próstata por ano, sendo que, na Região Centro-Oeste, se estimam 6.394 e, em Mato Grosso, 1.220 novos casos. ${ }^{(2-3)}$

O câncer de próstata ocorre quando há a multiplicação desordenada das células da próstata, dando origem a um tumor que pode se desenvolver rapidamente, atingir outros órgãos do corpo e levar à morte ou se desenvolver de uma forma lenta, demorando anos para atingir um $\mathrm{cm}^{3}$. ${ }^{(3-4)}$

Estudos apontam que sinais e sintomas do câncer de próstata são inespecíficos e silenciosos nos estágios iniciais. Nesse sentido, faz-se necessária a realização da triagem por meio dos 
exames de PSA e toque retal. Os sintomas mais comumente observados aparecem em estágios mais avançados, sendo comuns nos casos de câncer, mas também em situações de hiperplasia prostática benigna e são: disúria, noctúria e jato urinário fraco. ${ }^{(5-6)} \mathrm{O}$ rastreamento do câncer de próstata é realizado, segundo a Sociedade Brasileira de Urologia (SBU), a partir dos 40 anos para aqueles homens com histórico familiar de câncer de próstata e a partir dos 45 anos naqueles pacientes sem histórico. O MS, em parceria com o Instituto Nacional de Câncer (INCA), preconiza a sensibilização e o rastreamento desse tipo de câncer na faixa etária dos 50 a 70 anos de idade..$^{(1-3)}$ Homens com idade igual ou superior a 50 anos têm maior probabilidade de desenvolver a doença, visto que incidências e mortalidades aumentam a partir desta idade. $O$ câncer de próstata ameaça a saúde do público masculino por apresentar evolução lenta e sinais e sintomas passam despercebidos na fase inicial da doença, retardando o diagnóstico. ${ }^{(6)}$

O rastreamento deve ser realizado utilizando alguns critérios: estado clínico atual, queixas relacionadas à doença e histórico familiar. $\mathrm{O}$ rastreamento em massa pode, muitas vezes, expor o paciente a procedimentos desnecessários, gerando desconforto, ansiedade, aumento de diagnóstico falso positivo e, consequentemente, uso desnecessário de dinheiro público. Pactua com a ideia de que a assistência deve ser realizada de forma integral à saúde do homem, não se restringindo a campanhas anuais. ${ }^{(7)}$

Os homens, culturalmente, não têm o hábito de procurar o serviço de saúde para ações de prevenção contra o câncer de próstata. Geralmente, buscam atendimento perante manifestação de sinais e sintomas da doença. Muitos deles sofrem com as consequências da patologia, que poderia ser evitada com medidas preventivas, tornado o diagnóstico precoce fundamental para um bom prognóstico, pois a probabilidade de cura dessa doença pode ser diminuída com a detecção tardia. ${ }^{(8)}$

Alguns fatores impedem a busca pelo atendimento ao serviço de saúde, incluindo o medo da doença na forma avançada, pois não saber o diagnóstico pode se configurar como um fator de proteção psicológica. A vergonha em expor o corpo, particularmente a região anal, ao profissional de saúde, é outro fator limitante na busca por cuidado. Ressalta-se, também, a inexistência de serviços de saúde específicos para o atendimento da população masculina, pois a maioria dos serviços de saúde é destinada às mulheres, o que pode restringir a busca por atendimento dos homens. ${ }^{(8-9)}$

No âmbito da detecção precoce do câncer de próstata, fatores como o medo e o preconceito com o exame de toque retal vinculam o exame a uma fragilidade de sua masculinidade, fazendo com que haja uma diminuição da procura pelo exame de detecção da doença. ${ }^{(8)}$

Nesta perspectiva, este trabalho tem como objetivo compreender os significados do exame de próstata para o homem em situação de adoecimento crônico por câncer de próstata.

\section{Metodologia}

Trata-se de um estudo descritivo, exploratório, de abordagem qualitativa, que permite a compreensão e a capacidade de entender a experiência vivida pelo sujeito de acordo com sua realidade vivenciada. ${ }^{(10)}$

A abordagem qualitativa tem a finalidade de aprofundar e compreender um determinado fato, pois não se preocupa com representatividade numérica. A mesma possui como características a objetivação do fenômeno e a hierarquização das ações em que se segue a ordem de descrever, compreender e explicar determinado fato. A abordagem qualitativa permite compreender a realidade social, que trabalha com os significados do universo dos motivos, das crenças, das aspirações, dos valores e das atitudes. ${ }^{(11)}$

Este estudo foi realizado no município de Tangará da Serra - Mato Grosso, Brasil, que teve sua população estimada em aproximadamente 98.828 pessoas no ano de 2017.(12) A busca dos participantes deu-se por meio das Unidades de Saúde da Família (USF), onde se informaram casos de homens em situação de adoecimento por 
câncer de próstata. Posteriormente, eles foram selecionados por meio do enquadramento nos critérios de inclusão e exclusão da pesquisa e aceite em participar da mesma.

Os critérios de inclusão para participar do estudo foram: estar em situação de adoecimento por câncer de próstata; ter realizado o exame do toque retal há mais de seis meses; ter idade acima 45 anos; ser cadastrado em uma Unidade Básica de Saúde do município. Foram excluídos aqueles que não possuíam condições de sustentar a assinatura do Termo Consentimento Livre e Esclarecido (TCLE).

Para o levantamento dos dados, foram realizadas entrevistas abertas em profundidade onde se permitiu, ao sujeito, discorrer livremente sobre o tema proposto. Essas informações foram desenvolvidas por meio de um diálogo entre o entrevistador (um dos autores do estudo) e o sujeito, tratando de uma reflexão vivenciada pela realidade do mesmo. ${ }^{(11)}$ A coleta de dados foi realizada de março a agosto de 2017. As entrevistas partiram da questão norteadora: Conte-me como se deu a busca por cuidado desde o momento em que o senhor começou a sentir os sintomas? Nesta experiencia, como foi, para o senhor, realizar o exame de próstata?

As entrevistas foram realizadas até ocorrer a saturação dos dados. A saturação dos dados demonstra que, no trabalho de campo, em que novas entrevistas são coletadas, não surgem novas informações relevantes para a pesquisa onde os termos e categorias se tornam repetitivos. ${ }^{(11)}$

Os dados foram transcritos na íntegra pelo pesquisador. Na transcrição dos dados, o pesquisador deve representar os gestos, risos, entonação da voz do entrevistado, não sendo essa apenas um ato programado de transcrever no papel o discurso gravado, pois esses elementos presentes na gravação têm importância significativa para a análise, demonstrando informações sobre o entrevistado. ${ }^{(13)}$

Os dados foram analisados segundo a Análise Temática. A análise temática ou de conteúdo apresenta sinônimos de como é utilizado o termo triangulação, usado em diferentes situações, como, por exemplo: quando se empregam várias técnicas, métodos utilizados por profissionais de diferentes áreas que analisam o mesmo objeto. ${ }^{(14)}$

Este estudo fez parte de um projeto matricial intitulado "Experiência de busca por cuidado dos usuários dos serviços públicos de saúde em Tangará da Serra, Mato Grosso", aprovado pelo Comitê de Ética e Pesquisa Humana (CEP) da Universidade do Estado de Mato Grosso (UNEMAT) sob protocolo $\mathrm{N}^{\mathrm{o}}$ 1.328.397/2015. Durante todo processo de pesquisa, foi respeitada integralmente a resolução 466/2012 quanto a zelar pela legitimidade das informações, privacidades e sigilos. Todos os sujeitos tiveram seu anonimato resguardado, seus nomes foram substituídos pelo código " $\mathrm{H}$ " seguido por uma numeração ordinária conforme a ordem das entrevistas.

\section{Resultados e Discussão}

Baseado nas narrativas dos sete participantes deste estudo, apresentam-se as categorias temáticas que demonstram as percepções acerca da vivência em realizar o exame de toque retal como medida preventiva ao câncer de próstata.

Diante disso, emergiram duas categorias temáticas relacionadas à experiência dos homens submetidos ao exame de próstata: "Situações que influenciaram a realização ou não do exame de próstata e suas consequências"; "Percepções durante a realização do exame".

\section{Situações que influenciaram a realização ou} não do exame de próstata e suas consequências

O conhecimento prévio a respeito da doença foi um dos fatores relevantes identificados entre os participantes da pesquisa e influenciaram positivamente a decisão de realizar o exame de próstata. Eles conhecem e relatam que a hereditariedade constitui um fator de risco, que a realização do exame é indicada após os 45 anos e que, quando diagnosticada tardiamente e não tratada, uma das consequências é a morte, conforme apresentado nas narrativas a seguir. 
Oh, eu fiquei sabendo que, aos 45 anos, a gente era obrigado a fazer pra ver se não tinha problema na saúde; aí, eu fui no médico e conversei com ele: 'Não, vamos fazer o toque'; aí, fez o toque e aí tá tudo ok, fiquei muito feliz com isso. (H1)

Mas, hoje em dia, a gente sabe que deve fazer exame porque está morrendo muita pessoa de câncer de próstata. Fiz só uma vez já faz dois anos. Não fiz mais nenhuma vez, vou fazer o de sangue agora, vou pedir um pedido para mim fazer. (H3)

Nunca tive sintomas, fui fazer porque diz que é hereditário, né, se você tem na família, provavelmente um da família vai, por isso que eu faço, eu fiz com 48 anos, me atrasei um pouco, dai, continuei fazendo até hoje. $(\mathrm{H} 7)$

Pesquisas realizadas mostraram que os homens possuem conhecimentos sobre o câncer de próstata e a importância da realização do exame de toque retal, sendo que o conhecimento sobre a doença e o diagnóstico precoce é considerado ponto-chave para a prática preventiva. $\mathrm{O}$ reconhecimento da severidade da doença, realizar o exame precocemente e a preocupação com o câncer de próstata são os principais aspectos que conscientizam o homem sobre a importância da prevenção. ${ }^{(5,15)}$ Para rastrear o câncer de próstata, a Sociedade Brasileira de Urologia ${ }^{(16)}$ preconiza que o exame seja realizado com homens partir de 50 anos e que estes devem procurar um profissional especializado para a avaliação individualizada. Aqueles da raça negra ou com parentes de primeiro grau com câncer de próstata devem iniciar o rastreamento aos 45 anos. Para os homens com mais de 75 anos, poderá ser realizado apenas para aqueles com expectativa de vida acima de dez anos. O rastreamento deverá ser realizado após ampla discussão de riscos e potenciais benefícios, em decisão compartilhada com o paciente, visto que a universalização do exame de toda a população masculina (desconsiderando idade, raça e história familiar) é controversa, ao possibilitar o diagnóstico, entre outros, do câncer de próstata de baixa agressividade, que não demanda tratamento, cujos homens são submetidos a procedimentos como a biópsia, que tem potencial de complicações (infecção local) e, eventualmente, a tratamentos radicais com impacto exponencial na qualidade de vida. Ainda, o MS e o INCA preconizam a sensibilização e o rastreamento na faixa etária dos 50 a 70 anos de idade. ${ }^{(1-3)}$

O rastreamento deve ser realizado com cautela, não sendo encorajada a disseminação em massa sem a utilização de critérios para triagem, pois nem todos os pacientes com alterações no antígeno prostático específico (PSA) desenvolverão o câncer de próstata ou outra patologia. Dessa forma, com a utilização de critérios para o rastreamento, evita-se a exposição do paciente a procedimentos invasivos desnecessários, pois os mesmos podem gerar, além de complicações físicas, como a incontinência urinária e a disfunção erétil, sentimentos de ansiedade e medo, interferindo na qualidade de vida do homem. No entanto, o rastreamento tem sido alvo de críticas crescentes, porém, há entidades que reforçam a importância das campanhas preventivas ou de diagnóstico precoce. ${ }^{(7)}$

O incentivo da família foi considerado um aspecto motivacional para a realização do exame, sendo as esposas as principais incentivadoras para a busca pelo cuidado, conforme as narrativas a seguir.

A minha esposa pega muito no pé, sabe, para mim ir no médico; sou muito preguiçoso para ir no médico, aí, tenho plano de saúde, tem tudo e não queria ir no médico; aí, quando chegou a época, mandou eu fazer e leva eu lá pra fazer; ai a gente faz os exames. [...] mas ai minha mulher cobra muito, ai tenho que ir lá e fazer porque se cuidar, se prevenir melhor; ai vou ter que fazer de novo, já tá vencendo o prazo. (H1)

Procurei pra minha esposa, que é técnica de Enfermagem, né, falou: 'De uma forma ou de outra, vocêvaiterquepassar' (fazer exame). (H4)

Os homens casados procuram com mais frequência o serviço de saúde para o rastreamento de doenças devido ao estímulo da sua parceira, pois a parceira tem um papel fundamental no incentivo à busca pelo cuidado, sendo que essa desempenha 
desde cedo essa responsabilidade. Além disso, até os homens que realizaram o exame preventivo para rastreamento da próstata (PSA) ou o exame de próstata o fazem, muitas vezes, em virtude da persistência e incentivo dos familiares. ${ }^{(5,17)}$

A literatura corrobora ${ }^{(5,17)}$ os resultados desta pesquisa em que os homens consideram que a procura ao serviço de saúde está vinculada ao incentivo da esposa, pois a minoria dos homens busca atendimento por iniciativa própria.

Alguns sinais e sintomas, mesmo não sendo exclusivos ou causados pelo câncer de próstata, foram apontados pelos participantes do estudo como algo que os levou a fazerem o exame, tais como infecção do trato urinário (ITU), disúria e queimação ao urinar, como observado nas narrativas a seguir.

Eu tive uma infecção, ai o médico pediu pra eu procurasse um médico urologista, pra fazer o exame da próstata, ai eu fiz a ultrassom e aí fiz o toque também. (H4)

Eu estava com dificuldade de ir no banheiro para urinar, então, eu precisei procurar um médico. Qual o médico certo? Aí me encaminhou pra esse médico (urologista), então, me entreguei pra ele, né. Eu não vou para outro (médico). (H5)

O doutor mesmo veio e falou: 'Rapaz, deixa dá um toque aí!!!' Eu falei: 'Mas, doutor!? O senhor não está bem não (doutor)'. Eu falei que estava sentindo dor na urina, estava sentindo dor de cabeça, tudo que ele procurou pra mim, falei que estava sentindo. $O$ doutor falou: 'Você está doente, rapaz!' Eu falei: 'Não tô, doutor', teimei com ele, sabe, ai ele deu o toque e falou que estava desse tamanho assim (fez expressão com a mão, indicando o tamanho), já grande, né. (H2)

Pesquisa realizada em um Núcleo de Acolhida Especial (NAE), em João Pessoa - PB, no ano de 2014, afirmou que $40 \%$ dos homens sentiram algum sintoma relacionado ao trato urinário inferior. Os sintomas mais comumente observados relacionados ao câncer de próstata constituem hematúria e poliúria à noite, jato urinário fraco, dor ou queimação ao urinar. Eles só procuraram por atendimento de saúde após o surgimento dos sinais e sintomas que, em sua maioria, se apresentavam como infecção do trato urinário. ${ }^{(5)}$

A procura pelo serviço de saúde é maior entre as mulheres quando comparadas aos homens, visto que estes só buscam assistência quando o seu estado de saúde se encontra agravado ou em situações de emergência. Isso normalmente acontece porque os homens são preparados para ser fortes e protetores, nunca demonstrando suas impressões contrárias às mulheres. ${ }^{(18)}$

Percebe-se que situações de adoecimento por outras causas foram aproveitadas para a investigação do câncer de próstata, pois o homem somente procura por cuidados quando alguns sintomas já estão instaurados. Estudos indicam que os homens, em relação às mulheres, são mais vulneráveis às enfermidades graves e crônicas, situação de saúde que os leva a óbito mais precocemente que as mulheres. ${ }^{(5,8,18)}$

O preconceito em relação ao exame de toque foi unânime e ocorreu a "gozação" de familiares e amigos, como se pode observar nas narrativas a seguir.

Isso aí foi meio racismo meu, falo: 'Ah, não vou deixar o cara enfiar lá ne mim para dar toque nada'. (H2)

O sarro dos companheiros de serviço é terrível, foi um negócio terrível depois, até gente da familia mesmo, os sem vergonha dos sobrinhos diz que eu levei um buque de flor para o médico depois, tem que conformar, né, ai eles vêm falar que o dedo do médico é grosso, aí começa o preconceito, sabendo que todos eles têm que passar por aquilo ali uma hora, se cara querer ser machista e não querer passar, o cara vai a óbito por um pequeno tumor que se transforma em uma doença grave. (H5)

A gozação pega mesmo. O pior que tem, se você comenta com alguém que você fez o toque, ai se está lascado, ai a gozação pega mesmo. Principalmente em casa, com os filhos enchendo o saco, mas, dentro de casa, com os filhos, e depois, na rua, na época, eu mexia com bar, era comerciante, era ruim demais. Ai 
os clientes começava: 'Vai voltar no médico, gostou da dedada'; ai começa: 'O dedo era muito grosso', sacanagem mesmo, depois de vai embora levando, levando. (H6)

Normalmente, o homem traz consigo um imaginário machista onde há uma concepção de que seu corpo foi criado para penetrar e não ser penetrado. Desse modo, o exame de toque retal pode soar como homossexualidade. ${ }^{(19)}$

Infelizmente, a procura desse serviço ainda é reduzida por conta do déficit de conhecimento da população no que tange à prevenção ou até mesmo ao preconceito. ${ }^{(8)}$

As narrativas evidenciaram que os homens se sentem receosos ao exibir seu corpo para outro indivíduo do mesmo sexo. Assim, fica clara a existência do preconceito na comunidade em relação ao exame de toque por levantar questões culturalmente polêmicas como a sexualidade masculina frente ao exame.

A pesquisa revelou que os homens submetidos ao exame sofreram bastante "gozação" dos próprios amigos e familiares, tornandose um fator de dificuldade a adesão à busca pelo cuidado, sendo que a família deveria ser a principal incentivadora da busca pelo atendimento. Nas entrevistas também foram apontadas as consequências vivenciadas pela realização tardia do exame de toque retal, como se pode observar nas narrativas a seguir.

O cara vir a óbito por causa de uma pequena doença, talvez, o trem está no início, você vai e trata com remédio, você sara, depois que está com trem avançado, ai se acaba sendo prejudicado, indo até a óbito com câncer da próstata. (H5)

Ah, foi um desastre falar que está doente é tão ruim, né, exame da próstata e aí já veio para câncer, né. Pode atender que vai dar câncer em você, já estava no começo de câncer e estava mesmo. Ai operou e deu isso que falei para você, uso fralda, fica escorrendo direto, não parou e não vai parar, isso aqui parar, sabe o que vai acontecer? Disse que eu tenho que comprar um anelzinho pra colocar, mas esse anelzinho custa 80 mil reais, onde vou aguentar isso, não tem condição. (H2)

Meu pai teve, fez os exames e deu, ficou usando aquela bolsa durante dez anos, depois, não conseguiu mais e faleceu, não fez foi nada por causa do preconceito e a ignorância. $(\mathrm{H} 7)$

A busca tardia dessa população ao serviço de saúde pode estabelecer graves consequências, como descobrir a doença no estado mais avançado, diminuindo, assim, a chance de cura. Estudo realizado no Núcleo de Acolhida em João Pessoa$\mathrm{PB}$, no ano de 2014, evidenciou que $90 \%$ dos homens sabiam que o câncer de próstata pode levar a óbito após um diagnóstico tardio. ${ }^{(5,8)}$

Neste contexto, as narrativas apontam para a importância do diagnóstico precoce na prevenção de agravos à saúde. Em contrapartida, fica evidente que a demora na busca pelos serviços de saúde pode impactar tanto o prognóstico da doença, como em aspectos biopsicossociais e financeiros.

\section{Percepções dos homens durante o exame}

Nessa categoria, serão apresentadas narrativas que representam a vivência durante a realização do exame, destacando sentimentos como: houve constrangimento; desconforto; medo; as informações repassadas foram adequadas. Em contrapartida, outros entrevistados sentiram-se confortáveis para a realização do exame.

Na perspectiva dos entrevistados, é possível compreender que existe o constrangimento durante a realização do exame, que pode ser visto pelo homem como humilhação, como observado nas narrativas a seguir.

É constrangedor, viu, é humilhante aquilo, a gente faz porque tem que fazer, aquilo não é pra homem fazer não, é humilhante mesmo. (H6)

Foi um pouco chato, né, não foi fácil não, a primeira vez, né, mas é não era só eu, era vários pacientes que tinha na fila esperando. (H5)

Eu sou bem fechado pra esses tipos de coisas, pra fazer esse toque ai mesmo, eu ficava bem 
constrangido assim porque é uma coisa bem puxado para o homem em si [...] eu acho que é mais constrangedor ainda a pessoa fazer uma coisa dessa (toque) e depois ainda perguntar pra você se gostou do exame. (H4)

Os homens que passaram pelo exame de toque retal podem demonstrar resistência e se sentir intimidados, pois esse procedimento infringe sua masculinidade, sua condição de ser heterossexual. Essa situação acontece ainda hoje com os homens, pois veem esse exame como algo que denigre a imagem masculina. ${ }^{(20)}$

As narrativas acima demonstram que os homens que vivenciaram este exame experimentaram sentimento negativo que dificultou sua aceitação do exame. Os homens que realizaram o exame de próstata se sentiram muito constrangidos durante a realização do toque retal, além de se sentirem com vergonha, agonia, dor e inferioridade, pois isso interfere na sua masculinidade. Estudos afirmam que $52,9 \%$ dos casos apresentam esse sentimento de humilhação. ${ }^{(21)}$

Esta pesquisa evidenciou que os homens que realizaram o exame de toque retal se sentiram muito constrangidos e humilhados durante a realização do exame. Nas narrativas, também foram apontados casos em que a vivência da realização do exame se configurou como um momento tranquilo e ausente de sentimentos negativos.

O doutor chega, pede licença, ai fica na posição lá e tal, faz o que tem pra fazer. (H1)

Eu me senti bem porque não deu nada, né, tem um médico lá, mandou eu encostar, né, aí, deu o toque. (H3)

Mas tranquilo, muito igual, falavam é bem tranquilo, não é igual a gente pensa, né, bem à vontade, o médico relaxa a gente bastante, conversa bastante, aí, você fica bem à vontade [...] ficou só eu e ele na sala, não ficou mais ninguém e fiquei bem à vontade, né. (H4)

Percebe-se que se sentir bem e confortável em relação à realização do exame traz sentimentos de tranquilidade e despreocupação e estes são resultados de uma figura que traz apoio emocional, como a presença feminina, fé ou ainda confiança no profissional que realiza o exame. ${ }^{(8)}$

Assim, é preciso que o profissional de saúde realize um atendimento humanizado, tratando o paciente com respeito, que tenha um bom diálogo, que seja atencioso, fazendo com que o profissional ganhe a confiança do paciente e, assim, perceberá o quão importante é a realização do exame de toque retal..$^{(6,8)}$

Os participantes deste estudo afirmaram que, durante a realização do exame de toque retal, se sentiram confortáveis, pois o médico realizou um atendimento humanizado, explicando os procedimentos que seriam realizados, deixandoos, dessa forma, mais tranquilos para a realização do procedimento.

\section{Conclusão}

Este estudo evidenciou que existem fatores que influenciam positivamente a busca do cuidado, como o incentivo da família, considerado um aspecto motivacional para a realização do exame, sendo as esposas as principais incentivadoras para a busca do cuidado. O conhecimento prévio a respeito da doença é fundamental para a promoção de saúde e prevenção de agravos e para o diagnóstico precoce do câncer de próstata. Em contrapartida, o déficit de conhecimentos e o preconceito, tanto em relação ao procedimento quanto à "gozação" de alguns familiares e amigos, dificultam a busca pelos serviços de saúde. Em muitos casos, os pacientes buscam atendimento após o surgimento de sinais e sintomas, resultando em diagnóstico tardio, levando a um prognóstico desfavorável.

A partir dos resultados mostrados, os gestores e profissionais das áreas de saúde poderão fortalecer a Política Nacional de Atenção Integral à Saúde do Homem na Estratégia Saúde da Família (ESF), que objetiva a implementação de atendimentos humanizados, fortalecendo ações e serviços em rede e cuidados de saúde, incentivando para que os homens busquem pelo cuidado da própria saúde. Os profissionais de saúde têm papel fundamental 
para a adesão dessa população ao sistema de saúde por meio de ações educativas para fomentar o conhecimento sobre essa temática e ao proporcionar um cuidado humanizado por meio do acolhimento. $O$ enfermeiro atuante na APS deve priorizar a promoção e prevenção da saúde, aproximando esses profissionais da comunidade, favorecendo a formação de vínculo e garantindo, assim, maior adesão dessa população aos serviços de saúde.

\section{Referências}

1 Ministério da Saúde (BR). Portaria $\mathrm{n}^{\circ}$ 1.944, de 27 de agosto de 2009. Institui no âmbito do Sistema Único de Saúde (SUS), a Política Nacional de Atenção Integral à Saúde do Homem [Internet]. 2009 [citado 2018 set 8]. Disponível em: http://bvsms.saude.gov.br/bvs/ saudelegis/gm/2009/prt1944_27_08_2009.html

2 Instituto Brasileiro de Geografia e Estatística. Estimativa da população masculina para a cidade Tangará da Serra (MT) [Internet]. 2019 [citado 2020 abr 23]. Disponível em: http://www.cidades.ibge.gov.br/xtras/perfil. php?lang $=\& \operatorname{codmun}=510795 \&$ search $=$ matogrosso|tangara-da-serra

3 Instituto Nacional de Câncer (BR). Estimativas 2020 Incidência de câncer no Brasil: dados dos registros da incidência de câncer de próstata [Internet]. 2020 [citado 2020 abr 23]. Disponível em: https://www.inca.gov.br/sites/ufu.sti.inca. local/files/media/document/estimativa-2020incidencia-de-cancer-no-brasil.pdf

4 Serafim DP, Cardozo WML, Shumacher B. Homens com diagnóstico de câncer de próstata: enfrentamentos e adaptações. Rev Aten Saúde [Internet]. 2017 [citado 2018 jan 10]; 15(52): 2937. Disponível em: http://seer.uscs.edu.br/index. php/revista_ciencias_saude/article/view/4438/ pdf. doi: $10.13037 /$ ras.vol15n52.4438

5 Ribeiro LS, Lubenow JAM, Silva PE, Correia AA. Conhecimento de homens acerca da prevenção do câncer de próstata. Rev Ciênc Saúde Nova Esperança [Internet]. 2015 [citado 2018 jan 12]; 3(2): 4-10. Disponível em: http://www. facene.com.br/wp-content/uploads/2010/11/ Conhecimento-de-homens-PRONTO.pdf
6 Oliveira AJR, Silvestre JGO, Silva DC. A atuação da enfermagem frente às barreiras encontradas no diagnóstico precoce do câncer de próstata. Rev Eletrônica Ciênc Hum Saúde Tecnol [Internet]. 2016 [citado 2017 out 25];7(1):29-65. Disponível em: https://revista. fasem.edu.br/index.php/fasem/article/view/76

7 Modesto AADA, Lima RLB, Angelis AC, Augusto DK. Um novembro não tão azul: debatendo rastreamento de câncer de próstata e saúde do homem. Interface [Internet]. 2018 [citado 2018 jan 13];22(64):251-62. Disponível em: http://www.scielo.br/pdf/icse/ v22n64/1807-5762-icse-22-64-0251.pdf

8 Sousa MCP, Nogueira ARS, Lima CKS, Moreira IMSA, Sousa PCC, Elias CMV. Aspectos psicossociais associados aos exames de câncer de próstata em idosos. Rev Interdisciplin [Internet]. 2014 [citado 2018 fev 20];7(3):1-8. Disponível em: https:// revistainterdisciplinar.uninovafapi.edu.br/ index.php/revinter/article/view/450/pdf_151

9 Moura EC, Gomes R, Pereira GMC. Percepções sobre a saúde dos homens numa perspectiva relacional de gênero, Brasil. Ciênc Saúde Coletiva [Internet]. 2014 [citado 2017 nov 15];22(1):291-300. Disponível em: http:// www.scielo.br/pdf/csc/v22n1/1413-8123csc-22-01-0291.pdf

10 Gil AC. Métodos e técnicas de pesquisa social. 5a. ed. São Paulo: Atlas; 2011.

11 Minayo MCS. Amostragem e saturação em pesquisa qualitativa: consensos e controvérsias. Rev Pesqui Qualit [Internet]. 2017 [citado 2018 fev 22];5(7):1-12. Disponível em: https:// edisciplinas.usp.br/pluginfile.php/4111455/ mod_resource/content/1/Minayosaturacao.pdf

12 Instituto Brasileiro de Geografia e Estatística. Estimativa da população do município de Tangará da Serra (MT) [Intetnet]. 2017 [citado 2017 nov 10]. Disponível em: https:// cidades.ibge.gov.br/brasil/mt/tangara-daserra/panorama 
13 Araújo LFS, Dolina JV, Petean E, Musquin CA, Bellato R, Lucietto GC. Diário de pesquisa e suas potencialidades na pesquisa qualitativa em saúde. Rev Bras Pesqui Saúde [Internet]. 2013 [citado 2017 out 18];15(3):5361. Disponível em: http://periodicos.ufes.br/ RBPS/article/viewFile/6326/4660

14 Taquette SR, Minayo MC. Análise de estudos qualitativos conduzidos. Physis [Internet]. 2016 [citado 2017 nov 22];26(2):417-34. Disponível em: http://www.scielo.br/pdf/physis/ v26n2/0103-7331-physis-26-02-00417.pdf

15 Gomes CRG, Izidoro LCR, Mata LRF. Risk factors for prostate câncer, and motivational and hindering aspects in conducting preventive practives. Invest Educ Enferm [Internet]. 2015 [cited 2018 Jan 10];33(3). Available from: http://dx.doi.org/10.17533/udea.iee.v33n3a04

16 Sociedade Brasileira de Urologia. Nota oficial 2018: rastreamento do câncer de próstata [Internet]. 2018 [citado 2019 out 7]. Disponível em: https://portaldaurologia.org. br/area-da-saude/noticias/nota-oficial-2018rastreamento-do-cancer-de-prostata/

17 Mathias CV, Beuter M, Perlini NMOG. Experiência da família rural ao ter o pai/esposo com câncer de próstata. Rev Rene [Internet]. 2015 [citado 2018 fev 9];16(4):486-95. Disponível em: http://periodicos.ufc.br/rene/ article/view/2740/2123

18 Abreu AS, Cruz ACA, Cortez EA, Pereira FS, Nascimento RMS. Estratégias para a prevenção do câncer de próstata. Rev Pesqui Cuid Fundam [Internet]. 2013 [citado 2018 maio 15];5(2):3795-807. Disponível em: http://dx.doi.org/10.9789/21755361.2013v5n2p3795

19 Paiva EP, Motta MCS, Griep RH. Conhecimentos, atitudes e práticas acerca da detecção do câncer de próstata. Acta Paul Enferm [Internet]. 2010 [citado 2018 fev 15];23(1):88-93. Disponível em: http://www. scielo.br/pdf/ape/v23n1/14.pdf
20 Freitas MEM, Soares T, Souza LPS, Alcântara DDF, Silva CSO, Barbosa HA. Exame de toque retal: a percepção de homens quanto à sua realização. Rev Enferm UFPI [Internet]. 2015 [citado 2017 out 26];4(4):8-13. Disponível em: http://www.ojs.ufpi.br/index.php/reufpi/ article/view/3461/pdf

21 Costa TB, Moura, VF. O significado do toque da próstata para o homem: enfermeiro na promoção da saúde. Rev Pesqui Cuid Fundam [Internet]. 2013 [citado $2017 \mathrm{dez}$ 15];5(4):537-46. Disponível em: http://dx.doi. org10.9789/2175-5361.2013v5n4p537 